Matthias RiedEL, Salvatore TOMARCHIO

\title{
RETRACTION - A contribution to the Ichneumoninae fauna of Sicily (Hymenoptera Ichneumonidae)
}

We herein joint refer to the publication: Matthias Riedel, Salvatore Tomarchio (2012) A contribution to the Ichneumoninae fauna of Sicily $(\mathrm{Hy}-$ menoptera Ichneumonidae), Bollettino della Società entomologica italiana, 144 (3): 125-135, for properly retract the article according to the "Guidance from the Committee on Publication Ethics" (COPE, 2009). The reasons for invoking the retraction of the subject paper are based on an unethical approach for the use of the primary scientific data sources. In fact, the data taken from Turrisi G.F. collection (full property of Turrisi G.F. and only temporarily stored at ZSM-Zoologische Staatssammlung Munchen, Germany) have been used without the previous permission of the rightful owner and without taking into account the ongoing researches on the same material by G.F.Turrisi, belonging to a well raised project in cooperation with the staff at ZSM, namely with Prof. Klaus Schoenitzer and Dr Erich Diller, as stated by official published publication and documented stages attended by Turrisi G.F. at ZSM.

Both the Authors, according with Turrisi G.F., agree to invalidate the publication by Riedel \& Tomarchio (2012) according the ethic law, in order to establish the rightness for the use of the data and to release the two Authors from any responsibility for improper use of the scientific data of Turrisi G.F. entomological collection.

\section{REFERENCE}

COPE Committee on Publication Ethics, 2009 - Retractions: Guidance from the Committee on Publication Ethics (COPE). http://publicationethics.org/resources/guidelines. 